\title{
Foetal kidney length as a parameter for determination of gestational age in pregnancy by ultrasonography
}

\author{
Sunipa Chatterjee ${ }^{1}$, Kamlesh Yadav ${ }^{1}$, Parul Prakash ${ }^{1}$, Kirti Shekhawat ${ }^{2}$ *
}

${ }^{1}$ Department of Obstetrics and Gynaecology, SP Medical College, Bikaner, Rajasthan, India
${ }^{2}$ Department of Preventive and Social Medicine, SP Medical College, Bikaner, Rajasthan, India

Received: 10 April 2016

Received: 07 May 2016

Accepted: 10 May 2016

\author{
*Correspondence: \\ Dr. Kirti Shekhawat, \\ E-mail: researchoraclebikaner@gmail.com
}

Copyright: () the author(s), publisher and licensee Medip Academy. This is an open-access article distributed under the terms of the Creative Commons Attribution Non-Commercial License, which permits unrestricted non-commercial use, distribution, and reproduction in any medium, provided the original work is properly cited.

\begin{abstract}
Background: Establishing the gestational age of the fetus, especially in late trimester is a challenge to aptly treat the pregnant woman. Ultrasound parameters like BPD, HC, AC and FL in second and third trimesters are not very reliable for dating the pregnancy. Fetal kidney length has been studied and shown to strongly correlate with the gestational age in late trimesters even in IUGR fetuses.

Methods: This cross section hospital based study was conducted in the Department of Obstetrics and Gynecology, P.B.M. and Associated Group of Hospitals, attached to Sardar Patel Medical College, Bikaner during study period of one year from 2015 to 2016. 100 pregnant women with known dates of different parity and ages were included in this study.

Results: According to the observations, the mean deviation from the gestational age at all the weeks is least for KL. The result indicates that the kidney length in the present study correlated well with the assigned gestational age and found almost same as all the ultrasound biometric parameters put together.

Conclusions: Kidney length can be used as an individual parameter in estimating gestational age, especially in later trimesters, where biometric indices may not be much reliable.
\end{abstract}

Keywords: Pregnancy, Kidney length, Ultrasound, Gestational age

\section{INTRODUCTION}

From time immemorial there has been search for a single ultrasonographic parameter to determine the appropriate gestation of the fetus which is not affected by IUGR. As accurate age of fetus plays a pivotal role in obstetric care, uncertain dates and no assigned ultrasound dates in early trimesters poses a dilemma in management decisions leading to iatrogenic pre or post maturities. In high risk pregnancies like preeclampsia, IUGR, GDM, planning termination of pregnancy due to complications or to plan for fetal investigations or therapy requires an accurate gestational age. There are number of parameters used to calculate gestational age, but most commonly used by all sonologists is a composite GA obtained by BPD, HC, AC and FL in second and third trimesters. Even these may not provide GA with great accuracy owing to the discrepancies in late trimester scans and IUGR. ${ }^{1}$

Fetal kidney has been shown a steady growth of $1.7 \mathrm{~mm}$ fortnightly throughout pregnancy and is unaffected by growth abnormalities. ${ }^{2}$ Various studies have reported that fetal kidney length strongly correlates with the gestational age in late trimesters. Hence, this descriptive study was undertaken in the department of Obstetrics \& Gynaecology, SP Medical College, Bikaner, Rajasthan India to evaluate the application and accuracy of fetal kidney length measurement in determining the gestational age of the fetus as compared to that of other fetal biometric indices. 


\section{METHODS}

This cross section hospital based study was conducted in the Department of Obstetrics and Gynecology, P.B.M. and Associated Group of Hospitals, attached to Sardar Patel Medical College, Bikaner during study period of one year from 2015 to 2016. 100 pregnant women with known dates of different parity and ages were included in this study.

The women were evaluated as per history, general physical examination and routine antenatal investigations and using third trimester ultrasonography, mean fetal kidney length along with fetal head circumference, femur length, abdominal circumference and biparietal diameter were measured. Gestational age was calculated from mean fetal kidney length using normogram by Cohen et al. $^{3}$ These values were then compared with actual gestational age derived from actual dates taken as a standard.

The subjects were informed about the study and informed consent was taken before they enrolled in the study.

\section{Inclusion criteria}

1. All cases with singleton pregnancies in the third trimester (28 to 40 weeks).

2. Cases who were sure of the dates of their last menstrual period.

3. Normal antenatal pregnant women with no associated risk factors.

\section{Exclusion criteria}

1. Anomalous fetus

2. IUGR

3. Pregnant women with unknown dates

4. Off-springs of diabetic mothers

5. Renal pelvic dilatation of $5 \mathrm{~mm}$ or greater.

6. Twin pregnancies.

7. Renal anomalies or known case of renal anomalies

\section{RESULTS}

Table 1: Distribution of cases showing Kidney Length (KL) for various gestational ages.

\begin{tabular}{|llll|}
\hline $\begin{array}{l}\text { Gestational age in } \\
\text { weeks }(n=100)\end{array}$ & $\begin{array}{l}\text { Mean KL } \\
\text { in mm }\end{array}$ & SD & Median \\
\hline $28\left(\mathrm{n}_{1}=5\right)$ & 28.00 & 0.00 & 28.00 \\
\hline $29\left(\mathrm{n}_{2}=2\right)$ & 29.00 & 0.00 & 29.00 \\
\hline $30\left(\mathrm{n}_{3}=6\right)$ & 29.67 & 0.51 & 29.00 \\
\hline $31\left(\mathrm{n}_{4}=7\right)$ & 30.28 & 0.48 & 30.00 \\
\hline $32\left(\mathrm{n}_{5}=5\right)$ & 32.00 & 0.00 & 32.00 \\
\hline $33\left(\mathrm{n}_{6}=9\right)$ & 32.88 & 0.33 & 32.00 \\
\hline $34\left(\mathrm{n}_{7}=9\right)$ & 33.44 & 0.52 & 33.00 \\
\hline $35\left(\mathrm{n}_{8}=16\right)$ & 34.68 & 0.47 & 34.00 \\
\hline $36\left(\mathrm{n}_{9}=17\right)$ & 35.76 & 0.56 & 35.00 \\
\hline $37\left(\mathrm{n}_{10}=17\right)$ & 36.76 & 0.43 & 36.00 \\
\hline $38\left(\mathrm{n}_{11}=5\right)$ & 37.40 & 0.54 & 37.00 \\
\hline $39\left(\mathrm{n}_{12}=1\right)$ & 38.00 & 0.00 & 38.00 \\
\hline $40\left(\mathrm{n}_{13}=1\right)$ & 40.00 & 0.00 & 40.00 \\
\hline
\end{tabular}

Table 2: Regression equation application between KL versus GA.

\begin{tabular}{|c|c|c|c|c|c|c|c|c|c|}
\hline & & $\begin{array}{l}\text { Intercept } \\
\text { estimate }\end{array}$ & $\begin{array}{l}\text { Intercept } \\
\text { SE }\end{array}$ & $\begin{array}{l}\text { Slope } \\
\text { estimate }\end{array}$ & $\begin{array}{l}\text { Slope } \\
\text { SE }\end{array}$ & $\mathbf{R}^{2}$ & $\mathrm{SE}_{\mathbf{P}}$ & $P$ value & Conclusion \\
\hline $\begin{array}{l}\text { KL } \\
\text { v/s } \\
\text { GA }\end{array}$ & $\mathrm{N}=100$ & 0.3016 & 0.3434 & 9.907 & 0.0998 & 0.9899 & 0.2814 & $<0.001$ & $\begin{array}{l}\text { Highly significant } \\
\text { correlation between } \\
\text { KL and GA } \\
\text { (highest strength of } \\
\text { association among } \\
\text { these } 3 \\
\text { measurements*) }\end{array}$ \\
\hline
\end{tabular}

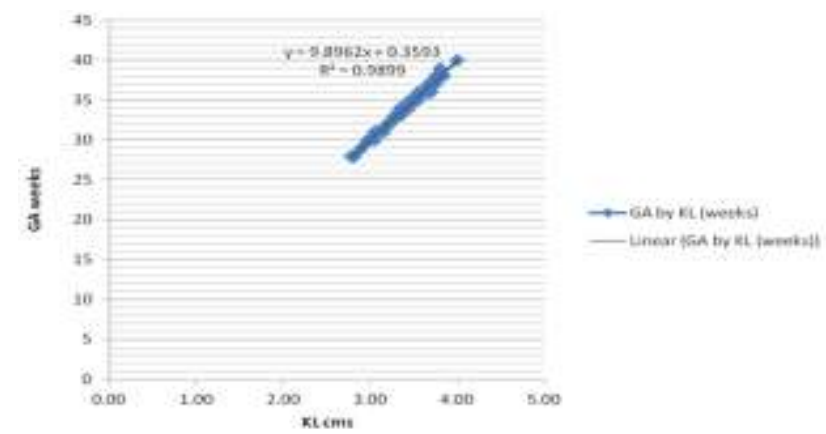

Figure 1: Correlation between KL and GA (weeks).
100 women were selected to complete the study with the ages ranging from 18-34 years. There was no difficulty in identification of kidney and taking appropriate measurements.

Table 1 showing distribution of cases showing KL for various gestational ages. In present study, gestational age was ranging from 28 to 40 weeks and their mean kidney length was ranging from 28.00 to $40 \mathrm{~mm}$. Maximum number of cases was found in gestational age 36 and 37 weeks $(n=17$ each) while least common gestational age was 39 and 40 weeks, where only 1 patient was found in each. 


\section{DISCUSSION}

This study was mainly done to measure the normal length of fetal kidneys sonographically during $3^{\text {rd }}$ trimester of pregnancies in all the cases of study. The greatest fetal kidney length of each of 100 consecutive fetuses between 27 to 40 weeks gestation was measured on sonogram. Abnormal fetuses, twins, offspring of diabetic mothers and fetuses with renal pelvic dilatation of $4 \mathrm{~mm}$ or greater were excluded to avoid any questionable measurements.

The range of mean fetal kidney length was from $22 \mathrm{~mm}$ at 22 weeks to maximum of $39 \mathrm{~mm}$ at 39 weeks at gestation, along with standard deviation and their 95\% confidence interval. According to our study the fetal kidney lengths in $\mathrm{mm}$ are almost equal to the weeks at a particular gestational age i.e. at 22 weeks of gestation (according to PA); the fetal kidney length was $22 \mathrm{~mm}$. It is also evident from this study that as the gestational age increases, the length of fetal kidney also increases and there is significant difference in the mean fetal kidney length that is found when lengths are compared across the 22 to 39 weeks of gestational age $(0<0.001)$. Kurtz et al in their review of studies of obstetrical measurements in ultrasound, noted only two earliest studies of fetal kidney length, that used renal time equipment. ${ }^{4}$ Two studies i.e. Bertagneli et al and Lawson et al showed their measurement almost equal to our study, and suggested a rule of thumb that is renal length in millimetres approximates gestational ages in weeks. ${ }^{5,6}$

The study by Bertagnoli et al and their chart were recommended. ${ }^{5}$ The reference articles showed, that mean length increases with gestational age. The study of Lawson et al using articulated arm scanning, showed measurement of $32 \mathrm{~mm}$ at 30 weeks and measurement of 42-43 $\mathrm{mm}$ at term, which are closer to our measurements. ${ }^{6}$

The study of Cohen et al, reported in their sonographic study of 397 obstetric patients, showed mean renal length of $27 \mathrm{~mm}$ at 22 weeks and of $42 \mathrm{~mm}$ at 39 weeks of gestation. ${ }^{7}$ These findings are greater and confidence intervals are wider than our study and previously reported.

Ansari et al also in their sonographic study of 793 fetus for measurement of normal fetal kidney length in Bangladesh reported that the average fetal kidney length of full term is $39.5 \mathrm{~mm}$. The findings are similar to our study. ${ }^{8}$

According to Konje et al the estimation of gestation age by foetal kidney length measurements was \pm 1 week at 2434 weeks of gestation and \pm 2 weeks at 34 -38 weeks of gestation. These findings are closely related to findings of our study. ${ }^{9}$

Although renal dilatation as great as $10 \mathrm{~mm}$ may be considered physiological and normal we arbitrarily decided to exclude kidneys with anterioposterior pelvic measurements greater than $4 \mathrm{~mm}$. We did so in order to avoid the possibility of considering pelvic dilatation, even if physiological, a reason for the longer length that we measured.

To confirm our measurement, Han and Babcock et al noted measurements of 39 to $59 \mathrm{~mm}$ in neonates. ${ }^{10}$ Fitzsimons showed measurement of neonatal kidneys among premature infants whose gestational age was determined by menstrual history, fetal sonographic measurements or maturity assessment were higher to those of our fetuses at equivalent gestational age, both our measurement and those of Fitzsomons showed little difference in the renal length measurement between weeks 22 to 40 we have no explanation for these findings. ${ }^{11}$

\section{CONCLUSION}

Kidney length can be used as an individual parameter in estimating gestational age, especially in later trimesters, where biometric indices may not be much reliable.

Funding: No funding sources

Conflict of interest: None declared

Ethical approval: The study was approved by the Institutional Ethics Committee

\section{REFERENCES}

1. Konje JC, Bell SC, Morton JJ, de Chazal R, Taylor DJ. Human fetal kidney morphometry during gestation and the relationship between weight, kidney morphometry and plasma active remain concentration as birth. Clin Sci. 1996;91:169-75.

2. Kansaria JJ, Parulekar SV. Nomogram for fetal kidney length. Bombay Hosp J. 2009;51(2):155-62.

3. Cohen HL, Cooper J, Eisenberg P, Mandel FS, Gross BR, Goldman MA, et al. Normal length of fetal kidneys: sonographic study in 397 obstetric patients. AJR Am J Roentgenol. 1991;157(3):545-8.

4. Kurtz AB, wapner RJ, Kurtz RJ. Analysis of biparietal diameter as an accurate indicator of gestational age. J Clin Ultrasound. 1980;8:319-26.

5. Bertagnoli L, Lalatta F, Gallicchio R. Quantitative characterized the growth of the fetal kidney. JCU. 1983;11:349-56.

6. Lawson T, Filey W, Berland L, Clark K. Ultrasonic Evaluation of lens kidneys : analysis of normal size and frequency of visualization as relevant to stage of pregnancy. Radiology. 1981;138:153-6.

7. Cohen HL, Cooper J, Eisenberg P, Mandel FS, Gross BR, Goldman MA, et al. Normal length of fetal kidneys: sonographic study in 397 obstetric patients. AJR Am J Roentgenol. 1991;157(3):545-548.

8. Ansari SM, Saha M, Paul AK, Mia SR, Sohel A, Karim R. Ultrasonic study of 793 foetuses. Measurement of normal fetal kidney length in Bangladesh. Australias Radiol. 1997;41(1):3-5. 
9. Konje JC, Okaro CI, Bell SC, DeChazal R, Taylor DJ. Evaluation of the accuracy and reliability of the use of fetal kidney length measurement in the determination of the gestational age after the 24th week of pregnancy. Ultrasound Obstet Gynecol. 1998.
10. Han B, Babcock D. Sonographic measurements and appearance of normal kidneys in children. AJR. 1985;145:611-6.

11. Fitzsimons R. Kidney length in the newborn measured by ultrasound. Acta Paediatr Scant. 1983;72:885-7.

Cite this article as: Chatterjee $\mathrm{S}$, Yadav K, Prakash $\mathrm{P}$, Shekhawat K. Foetal kidney length as a parameter for determination of gestational age in pregnancy by ultrasonography. Int J Reprod Contracept Obstet Gynecol 2016;5:1949-52. 